\title{
The frequency of rare and monogenic diseases in pediatric organ transplant recipients in Italy
}

Tiziana Vaisitti ${ }^{1 \dagger}$, Daniela Peritore ${ }^{2 \dagger}$, Paola Magistroni ${ }^{3}$, Andrea Ricci ${ }^{2}$, Letizia Lombardini ${ }^{2}$, Enrico Gringeri ${ }^{4}$, Silvia Catalano ${ }^{5}$, Marco Spada ${ }^{6}$, Marco Sciveres ${ }^{7}$, Angelo Di Giorgio ${ }^{8}$, Giuseppe Limongelli ${ }^{9}$, Marisa Varrenti ${ }^{10}$, Gino Gerosa ${ }^{11}$, Amedeo Terzi ${ }^{12}$, Carlo Pace Napoleone ${ }^{13}$, Antonio Amodeo ${ }^{14}$, Luca Ragni ${ }^{15}$, Luca Dello Strologo ${ }^{16}$, Elisa Benetti ${ }^{17}$, Iris Fontana ${ }^{18}$, Sara Testa ${ }^{19}$, Licia Peruzzi ${ }^{20}$, Adele Mitrotti ${ }^{21}$, Serena Abbate ${ }^{22}$, Giorgia Comai ${ }^{23}$, Eliana Gotti ${ }^{24}$, Marco Schiavon ${ }^{25}$, Massimo Boffini ${ }^{26}$, Daniele De Angelis ${ }^{27}$, Alessandro Bertani ${ }^{28}$, Domenico Pinelli ${ }^{29}$, Massimo Torre ${ }^{30}$, Camilla Poggi ${ }^{31}$, Silvia Deaglio ${ }^{1,3 *}$, Massimo Cardillo ${ }^{2}$ and Antonio Amoroso ${ }^{1,3}$ on behalf of Italian Pediatric Transplant Centers

\begin{abstract}
Background: Rare diseases are chronic and life-threatening disorders affecting $<1$ person every 2,000. For most of them, clinical symptoms and signs can be observed at birth or childhood. Approximately $80 \%$ of all rare diseases have a genetic background and most of them are monogenic conditions. In addition, while the majority of these diseases is still incurable, early diagnosis and specific treatment can improve patients' quality of life. Transplantation is among the therapeutic options and represents the definitive treatment for end-stage organ failure, both in children and adults. The aim of this paper was to analyze, in a large cohort of Italian patients, the main rare genetic diseases that led to organ transplantation, specifically pointing the attention on the pediatric cohort.

Results: To the purpose of our analysis, we considered heart, lung, liver and kidney transplants included in the Transplant Registry (TR) of the Italian National Transplantation Center in the 2002-2019 timeframe. Overall, 49,404 recipients were enrolled in the cohort, 5.1\% of whom in the pediatric age. For 40,909 (82.8\%) transplant recipients, a disease diagnosis was available, of which 38,615 in the adult cohort, while 8,495 patients (17.2\%) were undiagnosed. There were 128 disease categories, and of these, 117 were listed in the main rare disease databases. In the pediatric cohort, 2,294 (5.6\%) patients had a disease diagnosis: of the 2,126 (92.7\%) patients affected by a rare disease, 1,402 (61.1\%) presented with a monogenic condition. As expected, the frequencies of pathologies leading to organ failure were different between the pediatric and the adult cohort. Moreover, the pediatric group was characterized, compared to the adult one, by an overall better survival of the graft at ten years after transplant, with the only exception of lung transplants. When comparing survival considering rare vs non-rare diseases or rare and monogenic vs rare non-monogenic
\end{abstract}

\footnotetext{
*Correspondence: silvia.deaglio@unito.it

${ }^{\dagger}$ Tiziana Vaisitti and Daniela Peritore have contributed equally to this work.

1 Department of Medical Sciences, University of Torino, Via Nizza 52,

10126 Torino, Italy

Full list of author information is available at the end of the article
}

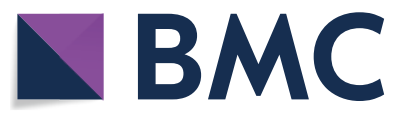

(c) The Author(s) 2021, corrected publication 2021. Open Access This article is licensed under a Creative Commons Attribution 4.0 International License, which permits use, sharing, adaptation, distribution and reproduction in any medium or format, as long as you give appropriate credit to the original author(s) and the source, provide a link to the Creative Commons licence, and indicate if changes were made. The images or other third party material in this article are included in the article's Creative Commons licence, unless indicated otherwise in a credit line to the material. If material is not included in the article's Creative Commons licence and your intended use is not permitted by statutory regulation or exceeds the permitted use, you will need to obtain permission directly from the copyright holder. To view a copy of this licence, visit http://creativecommons.org/licenses/by/4.0/. The Creative Commons Public Domain Dedication waiver (http://creativecommons.org/publicdomain/zero/1.0/) applies to the data made available in this article, unless otherwise stated in a credit line to the data. 
conditions, no differences were highlighted for kidney and lung transplants, while rare diseases had a better survival in liver as opposed to heart transplants.

Conclusions: This work represents the first national survey analyzing the main genetic causes and frequencies of rare and/or monogenic diseases leading to organ failure and requiring transplantation both in adults and children.

Keywords: Rare diseases, Monogenic diseases, Organ transplantation, Transplant outcome

\section{Background}

Rare diseases are chronic and debilitating disorders affecting a small number of people compared to the general population, with small differences in definition. In the USA, a disease is considered to be rare when it affects $<200,000$ people in the country, while in Europe the frequency is $<1$ in 2,000 people $(1,2)$. In addition, there are geographical issues, as diseases that are generally rare can be frequent in a specific population. For example, the congenital nephrotic syndrome of the Finnish type is generally a rare disease, with the exception of Finland, where it occurs more frequently than in other parts of the world (3). Although each rare disease affects a small number of patients, globally considered they result in roughly 400 million patients.

Approximately $80 \%$ of all rare diseases are genetic in origin and most of them display a family distribution compatible with a monogenic origin $(4,5)$, even though in a proportion of disorders the causative gene remains elusive $(5,6)$. In this context, the recent evolution and broader application of sequencing technologies have revealed the genetic causes of novel rare disease and led to the identification of new variants responsible for previously defined disorders (7).

Rare diseases are often progressive conditions and for most of them clinical symptoms and signs can be observed at birth or childhood, being responsible for $35 \%$ of deaths in the first year of life and a significant cause of pediatric hospital admissions (8-10). Moreover, in a considerable percentage of cases, they are severe multisystem disorders displaying a range of phenotypes with consequent diagnostic and patient management challenges. Notably, the great majority (95\%) of the 7,000-8,000 estimated rare diseases still lack FDA/EMEA approved therapies (11), even though symptomatic treatment and medical care can improve patients' quality of life and extend life expectancy.

Transplantation is one of the options and represents the definitive treatment for end-stage organ failure, both in children and adults. The advent of new immunosuppressive drugs and the improvement of surgical techniques have contributed to its widespread diffusion, which in turn has led to an expansion of medical indications and an increased organ need $(12,13)$.
This heightened demand, together with a non-proportional raise in organs availability, impose the ethical need that "no organ can be used for futile transplants or burdened by a poor prognosis" $(14,15)$. In 2019 , a total of 34,285 transplants were performed in Europe (21,235 kidney; 7,900 liver; 2,269 heart; 2,136 lung; 710 pancreas and 35 small bowel), which is however a small fraction when compared to the number of waiting listed patients in the same period $(109,739$ patients in total: 79,513 kidney; 16,007 liver; 6,940 heart; 4,883 lung; 2,313 pancreas and 83 small bowel) (16).

An open point in transplantation is the impact of rare diseases, specifically the ones with a genetic origin, since a significant percentage of end-stage organ failures are caused by monogenic pathologies $(17,18)$. Even though a wide variety of rare diseases benefit from solid organ transplantation, few reports address this topic from the genetic point of view.

The main aim of this paper is to analyze, in a large cohort of Italian patients, which are the main genetic diseases that lead to organ transplantation. Specifically, we aimed to shed light on pediatric transplantation, evaluating which among these pathologies lead more frequently to transplantation, the frequencies of rare and monogenic diseases and the organs involved. Finally, we analyzed the transplant outcome comparing patients with rare diseases-distinguishing even the most frequent monogenic ones - with those affected by rare non-monogenic diseases.

\section{Results \\ Cohort selection}

In the January 2002-December 2019 timeframe, the Transplant Registry (TR) of the National Transplantation Center database recorded 59,941 solid organ transplants, consecutively performed in Italy, of which 56,907 from cadaveric donors.

To the purpose of this study, due to low numbers, single pancreas $(n=1,146)$ and small bowel $(n=55)$ transplants were excluded from analysis, while re-transplanted patients were considered only once. Moreover, the cohort included recipients who underwent combined organ transplantation, both same organ (e.g., bi-pulmonary or bi-renal) and multi-organs (4,372 in total; Additional file 1: Table 1). Overall, our analysis, included kidney 
Table 1 Transplanted organ category and main features of the cohort included in the study

\begin{tabular}{|c|c|c|c|c|c|}
\hline & \multicolumn{5}{|c|}{ Transplanted organ } \\
\hline & Kidney & Liver & Heart & Lung & Total \\
\hline N. of transplants & 25,407 & 17,207 & 4,868 & 1,922 & 49,404 \\
\hline Without diagnosis of the original disease & 5,967 & 334 & 1,611 & 583 & 8,495 \\
\hline With diagnosis & 19,440 & 16,873 & 3,257 & 1,339 & 40,909 \\
\hline Adults & 18,553 & 15,836 & 2,981 & 1,245 & 38,615 \\
\hline Pediatrics & 887 & 1,037 & 276 & 94 & 2,294 \\
\hline N. of pediatric disease categories & 66 & 39 & 14 & 9 & 128 \\
\hline N. of pediatric diseases included in the rare disease catalogs & 61 & 35 & 13 & 8 & 117 \\
\hline N. of pediatric patients diagnosed with a rare disease & 840 & 920 & 273 & 93 & 2,126 \\
\hline N. of pediatric patients diagnosed with a monogenic disease & 411 & 686 & 223 & 82 & 1,402 \\
\hline
\end{tabular}

( $\mathrm{n}=25,407)$, liver $(\mathrm{n}=17,207)$, heart $(\mathrm{n}=4,868)$, and lung $(1,922)$ transplants, resulting in an enrolled cohort of $49,404$ recipients (Table 1$)$. In 40,909 (82.8\%) transplants, a definite diagnosis of disease leading to organ failure was available, of which 38,615 in the adult cohort and 2,294 in the pediatric one, while 8,495 patients (17.2\%) were present in the TR without a diagnosis. Transplants were performed in 47 Italian Transplant Centers, of which 34 involved in pediatric activities (Additional file 1: Table 2).

We then focused the attention on the pediatric cohort, defined as patients who were less than 18 years old when enrolled in the waiting list, and included in the TR with a disease diagnosis $(n=2,294)$. The mean age at the time of enrollment in the TR was 7.15 years, IQR [1-13 years], with differences when considering the type of organ (heart: 7.84; liver: 4.06; lung: 13.04; kidney: 9.86), while the mean age at the time of transplantation was 7.99 years, IQR [1-14].

To understand the impact of rare monogenic pathologies in this cohort, we matched the diseases categories entered in the TR with those listed in the main rare diseases databases. Based on TR data entries, overall, there were 128 disease categories: 66 for kidney, 39 for liver, 14 for heart and 9 for lung (Table 1). Of them, 117 were listed in the main rare disease databases. Within the pediatric cohort, 2,126 out of 2,294 (92.6\%) presented with a rare disease (840 kidney; 920 liver; 273 heart and 93 lung) of which 1,402 affected by a monogenic disease (411 kidney; 686 liver; 223 heart and 82 lung; Table 1).

Overall, the median follow-up from the transplant date was similar for the organs considered in the study: 6.73 years, IQR [2.48-10.57] for kidney; 5.39 years, IQR [1.23-8.87] for liver; 6.39 years, IQR [1.32-10.74] for heart; 3.6 years, IQR [0.39-5.62] for lung.

\section{Transplants in the Italian pediatric and adult cohorts: state of the art}

We then concentrated on patients with a clear diagnosis, looking at the distribution of transplants in the Italian cohort comparing the pediatric and adult groups, and taking in consideration i) transplanted organs, ii) main disease macro-categories that led to organ failure and iii) graft survival at 10 years after transplant. For the sake of clarity, this paragraph was divided in subparagraphs focused on the different transplanted organs.

Table 2 Heart transplant cohort and main disease categories leading to transplantation

\begin{tabular}{|c|c|c|c|}
\hline Disease macro-category & $\begin{array}{l}\text { Pediatrics (n. 276) } \\
\text { n. (\%) }\end{array}$ & $\begin{array}{l}\text { Adults (n. 2,981) } \\
\text { n. (\%) }\end{array}$ & $\begin{array}{l}\text { Total (n. 3,257) } \\
\text { n. (\%) }\end{array}$ \\
\hline Cardiomyopathies & $176(63.8)$ & $1,597(53.6)$ & $1,773(54.4)$ \\
\hline Congenital heart disease & $84(30.4)$ & $82(2.8)$ & $166(5.1)$ \\
\hline Valve heart disease & $5(1.8)$ & $161(5.4)$ & $166(5.1)$ \\
\hline Coronary disease & $3(1.1)$ & $939(31.5)$ & $942(28.9)$ \\
\hline Primary lung hypertension & $0(0.0)$ & $3(0.1)$ & $3(0.1)$ \\
\hline Other congenital pathologies & $3(1.1)$ & $7(0.2)$ & $10(0.3)$ \\
\hline Other cardio-circulatory diseases & $5(1.8)$ & $192(6.4)$ & $197(6.0)$ \\
\hline
\end{tabular}




\section{Heart}

For 3,257 heart transplanted patients $(66.9 \%$ of all heart transplants) a diagnosis was recorded in the TR; of them 276 were children (8.5\%) and 2,981 adults (91.5\%). While cardiomyopathies represented the first cause of disease both in children (63.8\%) and adults (53.6\%), coronary heart disease and valve heart disease were prevalent in adults (31.5\% vs $1.1 \%$ and $5.4 \%$ vs $1.8 \%$, respectively). On the other hand, children were significantly more affected by congenital heart disease than adults (30.4\% vs $2.8 \%)$. It is also noteworthy that in the adult group, a significant proportion of patients were affected by other cardio-circulatory diseases (5.8\%; Table 2).

When looking at graft survival, children had a better outcome than adults $(p<0.001$, Fig. 1a).

\section{Lung}

Of the 1,922 lung transplants, 1,339 (69.7\%) had a detailed disease diagnosis. The analysis therefore focused on 1,245 adults (93\%) and 94 pediatric cases (7\%; Table 1). In children, in line with recent published data (19), the most frequent cause of organ failure was cystic fibrosis $(79.8 \%)$, followed by primary pulmonary hypertension $(7.4 \%)$, congenital disorders and other pneumopathies (4.3\% each), which together accounted for $95.8 \%$ of cases. On the contrary, in adult patients, idiopathic pulmonary fibrosis was the most frequent cause of disease (35.9\%), followed by cystic fibrosis (28.4\%), emphysema/chronic obstructive pulmonary disease (18.4\%) and other pneumopathies (11.6\%). These 4 categories explained approximately $95 \%$ of cases (Table 3).

The success of lung transplantation was similar in pediatric and adult patients, with no significant differences at 10 years (Fig. 1b), even when excluding cystic fibrosis from the cohort (data not shown), in line with previously reported data (20).
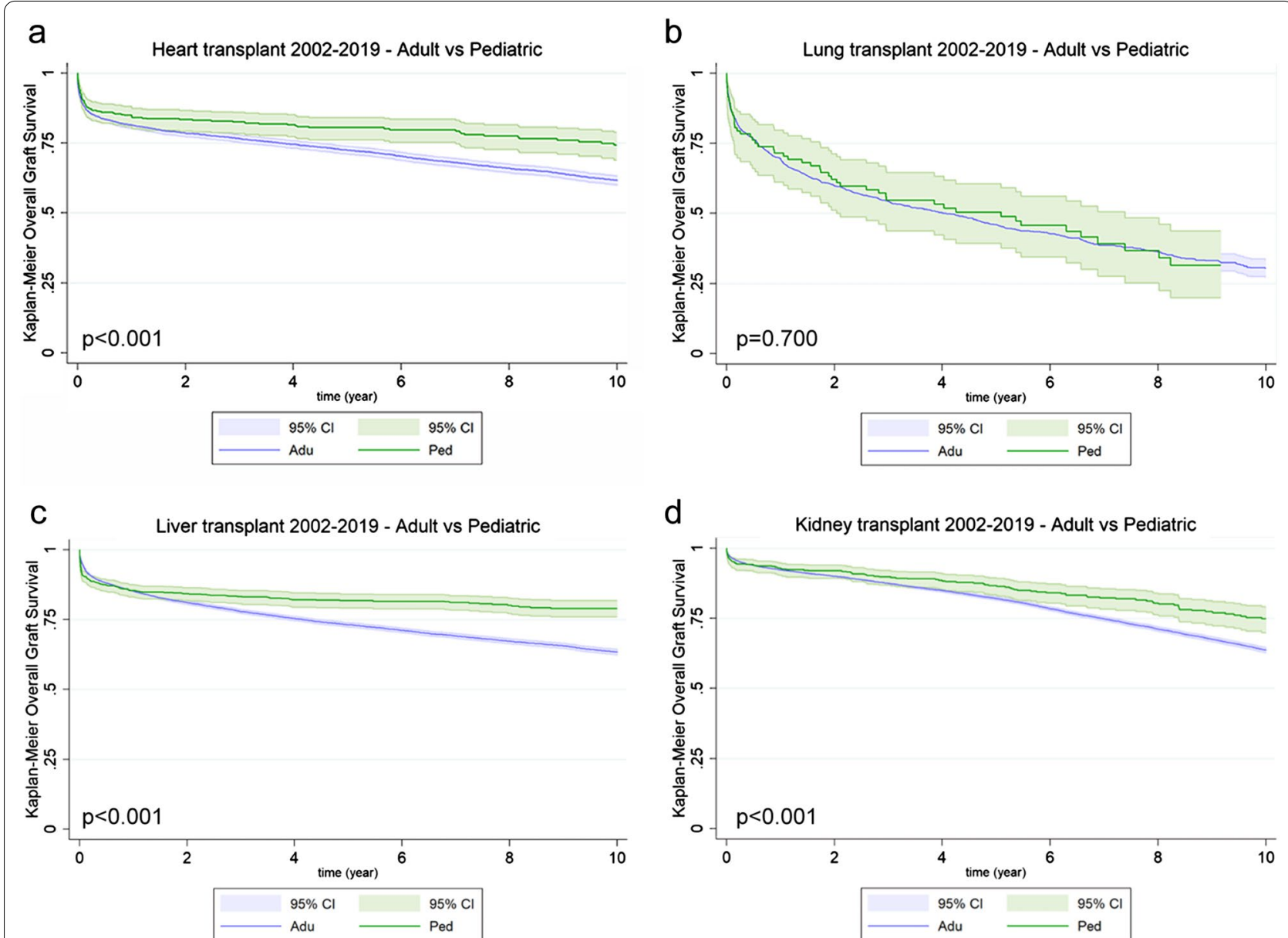

Fig. 1 Overall graft survival of transplanted patients in the 2002-2019 timeframe. Kaplan-Meier curves comparing adult (purple line) vs. pediatric (green line) transplanted cohort. Heart ( $p<0.001 ; 4248$ adults vs 403 children; a); Lung ( $p=0.700 ; 1445$ adults vs 94 children; b); Liver $(p<0.001$; $14,215$ adults vs 967 children; $c$ ) and Kidney ( $p<0.001 ; 17,588$ adults vs 817 children; $\mathbf{d})$ 
Table 3 Lung transplant cohort and main disease categories leading to transplantation

\begin{tabular}{llll}
\hline Disease macro-category & $\begin{array}{l}\text { Pediatrics (n. 94) } \\
\text { n. (\%) }\end{array}$ & $\begin{array}{l}\text { Adults (n. 1,245) } \\
\text { n. (\%) }\end{array}$ & $\begin{array}{l}\text { Total (n. 1,339) } \\
\text { n. (\%) }\end{array}$ \\
\hline Cystic fibrosis & $75(79.8)$ & $354(28.4)$ & $429(32.0)$ \\
Primary pulmonary hypertension & $7(7.4)$ & $51(4.1)$ & $58(4.3)$ \\
Other pneumopathies & $6(6.4)$ & $148(11.9)$ & $154(11.5)$ \\
Congenital disorders & $4(4.3)$ & $1(0.1)$ & $5(0.4)$ \\
Emphysema/Chronic obstructive pulmonary disease & $1(1.1)$ & $229(18.4)$ & $230(17.2)$ \\
Idiopathic pulmonary fibrosis & $1(1.1)$ & $447(35.9)$ & $448(33.5)$ \\
Congenital heart disease & $0(0.0)$ & $4(0.3)$ & $4(0.3)$ \\
Alpha-1 antitripsin deficiency & $0(0.0)$ & $11(0.9)$ & $11(0.8)$ \\
\hline
\end{tabular}

\section{Liver}

Out of the 17,207 liver recipients, 1,077 were performed in children $(6.3 \%)$ and 16,873 patients $(98.1 \%$ of cases) were registered in the TR with a diagnosis. There were 462 different disease definitions, which could be grouped into 9 diagnostic macro-categories, as shown in Table 4. Specifically, in the pediatric cohort, the most represented diseases were atresia of the biliary tract (41.8\%), other hepatopathies (17.3\%), metabolic diseases $(12.2 \%)$, cholestatic cirrhosis $(11.7 \%)$, and neoplasia $(8 \%)$, accounting for $94 \%$ of all cases. On the contrary, in adults, the most frequent diagnoses were non-cholestatic cirrhosis (37.6\%) and liver neoplasia (28.4\%), followed by alcoholic cirrhosis (10.6\%), cholestatic cirrhosis and cholestatic diseases (5.4\%), other liver diseases $(5.5 \%)$, accounting for $90 \%$ of all cases (Table 4).

When comparing the probability of graft success between the pediatric and adult cohort, the former presented an overall better survival than adults $(p<0.001$; Fig. 1c).

\section{Kidney}

Lastly, we analysed kidney transplants with 25,407 patients included in the TR. 19,440 recipients were registered with a disease diagnosis (76.5\%), of which the great majority $(95.4 \%)$ were adults with only 887 pediatric patients (4.6\%; Table 1). There were 568 different disease definitions, which could be grouped into 13 macro-categories (Table 5). In pediatric transplants, congenital familial nephro- and uropathies were the most represented pathologies ( $75.5 \%$ vs $2 \%$ in adults), followed by glomerular (10\%) and cystic (4.8\%) nephropathies. On the other hand, the most frequent pathologies in adult kidney transplants were glomerular nephropathies $(40.1 \%)$, followed by cystic nephropathies (18.8\%), other renal disorders (11\%), hypertensive nephrosclerosis $(8.7 \%)$, diabetic nephropathy $(7.6 \%)$ and tubular and interstitial nephropathies $(7.1 \%)$, the latter 3 macro-categories being almost absent in the pediatric cohort.

Kaplan-Meier curves of the overall graft survival referred to kidney and comparing the pediatric and adult cohorts, showed that the former one was characterized by a better outcome $(p<0.001$; Fig. $1 \mathrm{~d})$.

Table 4 Liver transplant cohort and main disease categories leading to transplantation

\begin{tabular}{|c|c|c|c|}
\hline Disease macro-category & $\begin{array}{l}\text { Pediatrics (n. 1,037) } \\
\text { n. (\%) }\end{array}$ & $\begin{array}{l}\text { Adults (n. 15,836) } \\
\text { n. (\%) }\end{array}$ & $\begin{array}{l}\text { Total (n. 16,873) } \\
\text { n. (\%) }\end{array}$ \\
\hline Hepatopathies from atresia of the biliary tract & $433(41.8)$ & $32(0.2)$ & $465(2.8)$ \\
\hline Metabolic diseases & $126(12.2)$ & $350(2.2)$ & $476(2.8)$ \\
\hline Cholestatic cirrhosis and other cholestatic liver diseases & $121(11.7)$ & $857(5.4)$ & $978(5.8)$ \\
\hline Neoplasia & $83(8.0)$ & $4,505(28.4)$ & $4,588(27.2)$ \\
\hline Acute liver necrosis & $44(4.2)$ & $404(2.6)$ & $448(2.7)$ \\
\hline Other non-cholestatic cirrhosis & $43(4.1)$ & $5,950(37.6)$ & $5,993(35.5)$ \\
\hline HBV/HCV related cirrhosis & $5(0.5)$ & $1,116(7.0)$ & $1,121(6.6)$ \\
\hline Alcoholic cirrhosis & $0(0.0)$ & 1,686 (10.6) & $1,686(10.0)$ \\
\hline Other hepatopathies & $182(17.5)$ & $936(5.9)$ & $1,118(6.6)$ \\
\hline
\end{tabular}


Table 5 Kidney transplant cohort and main disease categories leading to transplantation

\begin{tabular}{llll}
\hline Disease macro-category & $\begin{array}{l}\text { Pediatrics (n. 887) } \\
\text { n. (\%) }\end{array}$ & $\begin{array}{l}\text { Adults (n. 18,553) } \\
\text { n. (\%) }\end{array}$ & $\begin{array}{l}\text { Total (n. 19,440) } \\
\text { n. (\%) }\end{array}$ \\
\hline $\begin{array}{llll}\text { Congenital familial rare and metabolic based nephro- } \\
\text { and uro-pathies }\end{array}$ & $670(75.5)$ & $378(2.0)$ & $721(3.7)$ \\
Glomerular nephropathies & $89(10.0)$ & $7,438(40.1)$ & $7,527(38.7)$ \\
Cystic nephropathies & $43(4.8)$ & $3,493(18.8)$ & $3,536(18.2)$ \\
Acute renal insufficiency & $13(1.5)$ & $43(0.2)$ & $56(0.3)$ \\
Other familial nephropathies & $12(1.4)$ & $227(1.2)$ & $239(1.2)$ \\
Different nephro-vasculopathic and nephrosclerosis & $7(0.8)$ & $389(2.1)$ & $396(2.0)$ \\
syndromes & & & $55(0.3)$ \\
Kidney neoplasia & $2(0.2)$ & $53(0.3)$ & $1,611(8.3)$ \\
Hypertensive nephrosclerosis & $1(0.2)$ & $1,610(8.7)$ & $1,326(6.8)$ \\
Tubular and interstitial nephropathies & $0(0.0)$ & $1,326(7.1)$ & $1,409(7.2)$ \\
Diabetic nephropathy & $0(0.0)$ & $1,409(7.6)$ & $2(0.0)$ \\
Non-cholestatic cirrhosis & $0(0.0)$ & $2(0.0)$ & $4(0.0)$ \\
Other hepatopathies & $3(0.3)$ & $1(0.0)$ & $2,558(13.2)$ \\
Other kidney disorders & $47(5.3)$ & $2,184(11.8)$ & \\
\hline
\end{tabular}

\section{Rare and monogenic diseases frequencies in pediatric} transplanted patients and their impact on grafts survival In the last section of the work, we focused selectively on the pediatric cohort of transplanted patients, included in the TR with a clear diagnosis, with the aim of defining the frequencies of rare and/or monogenic diseases that were causative of organ failure, ultimately requiring organ transplantation. For the former group of pathologies, we firstly matched the main databases reporting these diseases to obtain a full list for each organ. Rare diseases are indicated with the Orphanet code. The diagnoses included in the TR were then classified according to disease categories in rare and rare monogenic diseases. As a last inquiry, we compared graft survival in patients affected by i) rare vs non-rare diseases, ii) rare monogenic vs rare non-monogenic diseases and finally iii) considering the most represented disease macro-categories for each organ.

13 out of 14 diseases categories responsible for heart transplantation in children were included in the rare disease catalogues, accounting for almost all pediatric patients with heart transplantation (273 out of 276 , 98.9\%), with 223 patients (82\%) diagnosed with a pathology belonging to monogenic diseases. The only condition found in pediatric cases that is not considered a rare disease was dilated heart disease on ischemic basis (3 patients). However, it is not possible to exclude with certainty that even in these cases a rare/monogenic pathology was involved, possibly due to disorders of lipid metabolism. The most represented pathology was dilated cardiomyopathy (42.8\% of cases), followed by congenital heart disease on a genetic basis (30.8\%), hypertrophic cardiomyopathy (8.3\%) and restrictive cardiomyopathy (7.6\%). Alone, these 4 disease categories represented $89 \%$ of pediatric transplants (Table 6).

If we distinguish pediatric transplants according to whether they have been performed because of a rare vs a non-rare disease, we noted that the probability of success was significantly better for transplants performed in children without rare diseases $(p<0.05$; Fig. $2 \mathrm{a})$. On the contrary, transplants performed because of a monogenic disease presented a significantly better chance of success $(p<0.05$; Fig. 2b). Finally, when considering the outcome of the transplant taking into account the 2 most represented groups of cardiac diseases, congenital pathologies and cardiomyopathies, no significant differences were highlighted between them, even though they showed a significant better profile compared to other cardiac pathologies ( $p<0.01$; Fig. 2c).

When analysing in detail the 9 different definitions of disease found in lung transplanted patients and classifying them according to rare diseases, we noted that almost all patients $(98.9 \%)$ were affected by rare diseases, of whom $86 \%$ of monogenic origin. Cystic fibrosis was the leading cause of lung failure, affecting $80.6 \%$ of the whole cohort. The second most frequent diagnosis was represented by pulmonary arterial hypertension, a rare disease of non-monogenic nature, counting $7.5 \%$ of patients.

(Table 7).

Since more than $50 \%$ of pediatric transplants were performed in recipients with cystic fibrosis, which is a rare and monogenic disease, further evaluations in relation to the outcome of pediatric transplants were strongly influenced by this single category. Moreover, due to an almost 
Table 6 Diagnostic categories in heart transplanted pediatric cohort and distribution between rare and monogenic diseases

\begin{tabular}{|c|c|c|c|c|}
\hline Diagnosis & ORPHA code & $\operatorname{Tx}($ (n. 276) & $\begin{array}{l}\text { Rare diseases }(\text { n. } 273) \\
\text { n. (\% respect to total Tx) }\end{array}$ & $\begin{array}{l}\text { Monogenic diseases }(\mathrm{n} .223) \\
\text { n. (\% respect to rare diseases) }\end{array}$ \\
\hline Complication following organ transplant & 306,644 & 1 & $1(0.4)$ & \\
\hline Dilated cardiomyopathy & 217,604 & 118 & $118(42.8)$ & $113(41.4)$ \\
\hline Dilated cardiomyopathy on ischemic basis & & 3 & & \\
\hline Ebstein malformation & 1880 & 1 & $1(0.4)$ & $1(0.4)$ \\
\hline $\begin{array}{l}\text { Familial isolated arrhythmogenic dysplasia of } \\
\text { the right ventricle }\end{array}$ & 217,656 & 1 & $1(0.4)$ & $1(0.4)$ \\
\hline Genetic heart disease & 271,853 & 85 & $85(30.8)$ & $84(31.1)$ \\
\hline Hypertrophic cardiomyopathy & 217,569 & 23 & $23(8.3)$ & \\
\hline Hypoplastic left heart & 2248 & 2 & $2(0.7)$ & $2(0.7)$ \\
\hline Myocarditis & $\S$ & 9 & $9(3.3)$ & \\
\hline Radiation-induced pathology & 521,132 & 5 & $5(1.8)$ & \\
\hline Restrictive cardiomyopathy & 217,632 & 21 & $21(7.6)$ & $21(7.6)$ \\
\hline Shone Complex & 99,063 & 1 & $1(0.4)$ & $1(0.4)$ \\
\hline Severe aortic insufficiency & 99,094 & 1 & $1(0.4)$ & \\
\hline Valvular heart disease & 228,410 & 5 & $5(1.8)$ & \\
\hline
\end{tabular}

Tx: transplants;

$\S$ : included in the NORD database ( https://rarediseases.org/rare-diseases/myocarditis/)

complete overlap between rare and monogenic diseases also in the remaining categories, we did not perform survival analyses. And indeed, the overall survival between cystic fibrosis diagnosed patients and all the other disease categories showed no differences $(p=0.653$; Fig. 3$)$, in line with previously reported data (19).

Regarding liver pediatric transplants, there were 39 different definitions of diseases available in the TR, with the great majority included in the catalogues of rare diseases (36 out of 39 disease categories, accounting for $90 \%$ of patients) and 17 out of 39 being of monogenic origin, including almost $71 \%$ of patients. Analyzing the distribution of these diagnoses, it was noted that the most frequent were congenital biliary disease/extrahepatic biliary atresia (41.1\% of patients), cholestatic diseases (11.5\%), metabolic diseases, including cystic fibrosis and primary hyperoxaluria (9.8\%), Alagille syndrome (4.5\%), and Wilson disease (1.7\%), which all together constituted approximately $70 \%$ of all cases (Table 8).The distribution in this cohort is slightly a bit different from the ones previously reported by Fagiuoli and colleagues, where the dominant phenotype was represented by Alagille syndrome (21).

Pointing the attention on the graft survival of pediatric liver transplants, those performed in patients with rare diseases showed a significantly better outcome compared to patients with common diseases $(p<0.005$; Fig. $4 a)$. On the contrary, no differences were noted when dividing them based on the presence or absence of a monogenic disease ( $\mathrm{p}=0.87$; Fig. $4 \mathrm{~b})$. When plotting graft survival according to the main diagnostic categories, globally considered, no statistically significant differences were highlighted $(\mathrm{p}=0.11)$. However, a trend towards a better outcome could be noted for metabolic diseases, biliary atresia, and cholestatic diseases. On the contrary, transplants performed because of neoplasia and cirrhosis showed a worse overall survival (Fig. 4c).

Lastly, we looked at kidney transplants in the pediatric cohort. The list contained 66 different disease categories, most of which $(n=62)$ included in the catalogues of rare diseases. Overall, $94.7 \%$ of transplanted patients had a diagnosis of rare disease and half of these ones (46.3\%) had a monogenic origin. The most represented diseases were renal or urinary tract malformation (36.9\%), followed by focal segmental glomerulosclerosis (8.1\%), nephronophthisis $(8 \%)$, autosomal recessive polycystic kidney disease (4.8\%), glomerulonephritis $(4.3 \%)$, congenital nephrotic syndrome Finnish type (3.8\%), Alport syndrome (3\%) and hemolytic uremic syndrome (2.9\%). It is worthy to note that monogenic diseases might be underestimated, as monogenic forms of renal or urinary tract malformation and glomerulonephritis are known (Table 9).

In pediatric kidney transplants and similar to what observed for lung transplants, no significant differences were highlighted when comparing rare vs common diseases $(p=0.36$; Fig. $5 a)$ or when considering monogenic vs non-monogenic diseases ( $p=0.33$; Fig. $5 b)$ at ten years after transplant. However, when plotting overall graft survival taking in consideration the most representative disease macro-categories, some significant differences 

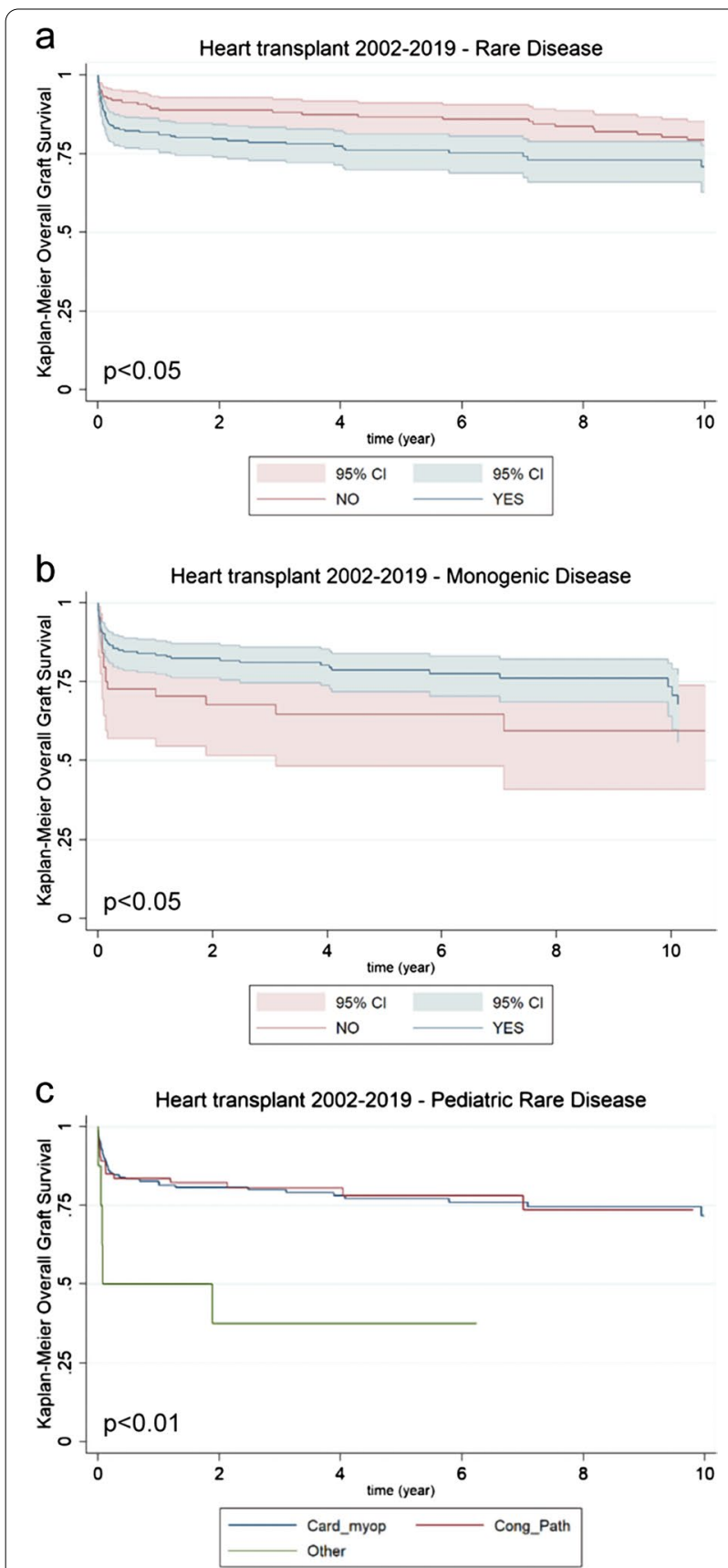

Fig. 2 Survival of heart transplanted patients in the 2002-2019 timeframe. a Kaplan-Meier curves comparing patients affected by rare diseases (green line; $n=240$ ) vs. patients affected by non-rare diseases (red line; $\mathrm{n}=163$ ) $[p<0.05]$. b Kaplan-Meier curves comparing patients affected by monogenic diseases (green line; $n=196)$ vs. patients affected by rare non-monogenic diseases (red line; $n=44)[p<0.05]$. c Kaplan-Meier curves comparing patients affected by cardiomyopathies (Card_myop; blu line; $n=158$ ) vs. congenital pathologies (Cong_Path; red line; $n=74$ ) vs. other pathologies (Other; green line; $\mathrm{n}=8$ ) $[p<0.01]$ appeared, with glomerular and congenital nephropathies showing the best outcome as opposed to renal and urinary tract abnormalities and focal segmental glomerulosclerosis $(p<0.01$; Fig. $5 c)$.

\section{Discussion}

An ample body of literature comes out when surfing PubMed using "transplantation" or "organ transplants" as search keywords. Different aspects are addressed and discussed, mainly referring to clinical and surgical topics, as well as to immunological issues. In the last year, even the impact of COVID-19 has represented a "hot topic" in transplantation $(22,23)$. In this paper, solid organ transplants are addressed and investigated from a genetic perspective, which is a relatively unexplored field $(17,18$, $24)$, thus strengthening the novelty of this work. We carried out a national survey, based on data included in the Italian Transplant Registry (TR), by focusing on disease causes that lead to organ failure thus finally requiring transplants. Specifically, we reported the Italian "state of the art", considering both the adult and pediatric cohorts, with the aim of comparing these two subsets of patients, highlighting the percentage of undiagnosed patients included in the TR, and describing the frequency and distribution of rare and monogenic diseases in transplants recipients. Several points of discussion can be raised from this analysis.

The first observation that comes to light concerns the percentage of patients included in the TR without a disease diagnosis. Considering all transplants, a diagnosis is recorded in $40,909(82.8 \%)$ resulting in a $17.8 \%$ of transplanted patients who remain undiagnosed, in line with previous data (25-27). When dividing by organs, heart and lung transplants present with the higher percentage of undiagnosed patients $(\mathrm{n}=1,611,33.1 \%$ and $\mathrm{n}=583,30.3 \%$, respectively), followed by kidney transplants $(n=5,967,23.5 \%)$, while only a minority of liver transplanted patients were without a diagnosis $(n=334$, $1.9 \%)$. A possible explanation for the higher percentage of diagnosed patients in TR for liver transplants compared to the other organs may rely on the structure of the TR, allowing for liver, and only for this organ, three different levels of diagnostic information to be recorded.

The second observation regards the quote of diagnosed pediatric transplants (2,294 patients in total, $5.6 \%$ of all diagnosed transplanted patients). Depending on the organ considered, the percentage of diagnosed patients varies, being the highest for heart (8.5\%), followed by liver (6.1\%) and lung (7.0\%). On the contrary, kidney presented the lower quote of diagnosed patients $(4.5 \%)$. It is noteworthy that the frequencies and distribution of pathologies leading to organ transplants are different between the adult and pediatric cohorts, especially when 
Table 7 Diagnostic categories in lung transplanted pediatric cohort and distribution between rare and monogenic diseases

\begin{tabular}{|c|c|c|c|c|}
\hline Diagnosis & ORPHA code & $\operatorname{Tx}(\mathrm{n} .94)$ & $\begin{array}{l}\text { Rare diseases ( } n .93 \text { ) } \\
\text { n. (\% respect to total Tx) }\end{array}$ & $\begin{array}{l}\text { Monogenic diseases ( } \mathrm{n} .82 \text { ) } \\
\text { n. (\% respect to rare diseases) }\end{array}$ \\
\hline Bronchiolitis obliterans & 1303 & 2 & $2(2.1)$ & \\
\hline Chronic obstructive pulmonary disease & & 1 & & \\
\hline Cystic fibrosis & 586 & 75 & $75(80.6)$ & 75 (80.6) \\
\hline Eisenmenger syndrome & 97,214 & 4 & $4(4.3)$ & $4(4.3)$ \\
\hline Idiopathic pulmonary fibrosis & 2032 & 1 & $1(1.1)$ & $1(1.1)$ \\
\hline Interstitial lung disease due to $\mathrm{ABCA} 3$ deficiency & 440,402 & 1 & $1(1.1)$ & $1(1.1)$ \\
\hline Langerhans cell histiocytosis & 389 & 1 & $1(1.1)$ & $1(1.1)$ \\
\hline Pulmonary arterial hypertension & 182,090 & 7 & $7(7.5)$ & \\
\hline Rejection/Complication after organ transplantation & 306,644 & 2 & $2(2.1)$ & \\
\hline
\end{tabular}

Tx: transplants

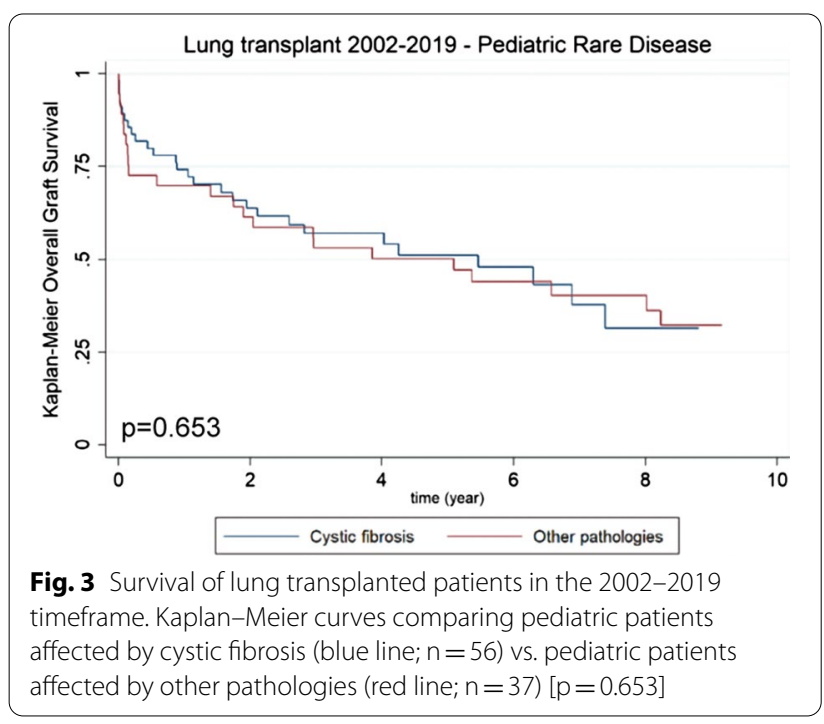

analysing kidney and liver transplants. Moreover, the quote of pediatric kidney transplants is lower compared to the other organs, when taking in consideration the overall number of transplants for each organ. This lower percentage is probably linked to different factors: firstly, kidney diseases may take a longer period of time to lead to organ failure. In line with this hypothesis, the mean age of enrollment in the TR is higher for kidney patients (9.86 years) compared to heart and liver ones (7.84 and 4.06 years, respectively). Secondly, kidney transplant does not represent a lifesaving treatment as other options can temporarily supply to organ dysfunction.

The third point of discussion is centred on the disease categories within the pediatric cohort. Overall, we listed 128 different diseases, with kidney transplants contributing the most to this catalogue (51.5\%), followed by liver (30.5\%), heart (10.9\%) and lung (7.0\%). However, it must be noted that the number of pediatric patients with diagnosis who underwent either a heart or lung transplant is relatively small. Interestingly, out of 128 disease categories identified, 117 are included in the main catalogues of rare diseases, meaning that 92.7\% of the pediatric cohort is affected by this type of diseases. This proportion varies slightly depending on the organ involved, being higher for thoracic organ transplants (98.9\%) compared to abdominal ones (94.7\% for kidney and $88.7 \%$ for liver). An interesting result that has been highlighted by this survey is that a considerable percentage $(65.9 \%)$ of the pediatric patients presenting with a rare disease is affected by a monogenic condition. As expected, lung, heart and liver transplants presented the higher quote of monogenic diseases $(88 \%, 81.7 \%$ and $74.6 \%$, respectively) at variance with kidney transplants, where $<50 \%$ of patients are affected by a disease of monogenic origin. This significant difference can be explained by the fact that within kidney, some categories of rare diseases may include a quote of monogenic pathologies (e.g., CAKUT, glomerulonephritis) thus leading to an underestimation of the real percentage. The distribution of affected patients seems to be independent of the sex in heart and liver transplants, while a clear association was present for lung and kidney ones. In the first case, there was a prevalence $(63.8 \%)$ of female patients likely reflecting the fact that the great majority of the cohort was affected by cystic fibrosis. Several papers in literature suggest that a sex dichotomy exists for this disease, despite improved therapies, with female patients experiencing a slightly worse prognosis, both in terms of mortality and susceptibility to chronic infections (28$31)$. On the contrary, for kidney transplants, there was a prevalence of male subjects (61.8\%). In part, these data can be explained by the fact that some diseases are characterized by an X-linked mode of inheritance (e.g., Alport syndrome) thus affecting male subjects. Beside the genetic aspect, these data are in line with evidence 
Table 8 Diagnostic categories in liver transplanted pediatric cohort and distribution between rare and monogenic diseases

\begin{tabular}{|c|c|c|c|c|}
\hline Diagnosis & ORPHA code & $\operatorname{Tx}(\mathrm{n} .1,037)$ & $\begin{array}{l}\text { Rare diseases ( } \mathrm{n} .904) \\
\text { n. (\% respect to total Tx) }\end{array}$ & $\begin{array}{l}\text { Monogenic diseases (n. } 689) \\
\text { n. (\% respect to rare diseases) }\end{array}$ \\
\hline $\begin{array}{l}\text { Acute liver failure_-Fulminant or subfulminant } \\
\text { hepatic failure }\end{array}$ & & 53 & & \\
\hline Alagille syndrome & 52 & 47 & $47(4.5)$ & $47(5.2)$ \\
\hline Alpha-1 antitrypsin deficiency & 60 & 11 & $11(1.1)$ & $11(1.2)$ \\
\hline Angiosarcoma (neoplasia) & 263,413 & 1 & $1(0.1)$ & \\
\hline Budd-Chiari syndrome & 131 & 5 & $5(0.5)$ & $5(0.5)$ \\
\hline Caroli disease & 53,035 & 6 & $6(0.6)$ & \\
\hline Cholestatic disease-Primary biliary cirrhosis & 186 & 17 & $17(1.6)$ & \\
\hline Cholestatic disease_-Primary sclerosing cholangitis & 171 & 42 & $42(4.1)$ & \\
\hline Cholestatic disease-Other & & 27 & & \\
\hline Cholestatic disease_-Secondary biliary cirrhosis & 447,774 & 29 & $29(2.9)$ & \\
\hline Cirrhosis-Autoimmune & 779 & 8 & $8(0.8)$ & \\
\hline Cirrhosis-Other & & 10 & & \\
\hline Cirrhosis - Virus related & & 11 & & \\
\hline $\begin{array}{l}\text { Congenital biliary disease-Extrahepatic biliary } \\
\text { atresia }\end{array}$ & 498,345 & 426 & $426(41.1)$ & $426(47.1)$ \\
\hline Crigler-Najjar syndrome type 1 & 79,234 & 4 & $4(0.4)$ & $4(0.4)$ \\
\hline Cryptogenic cirrhosis & & 24 & & \\
\hline Epithelioid hemangioendothelioma (neoplasia) & 157,791 & 3 & $3(0.3)$ & \\
\hline Familial hypercholesterolemia & 391,665 & 1 & $1(0.1)$ & \\
\hline Glycogen storage disease & 79,201 & 6 & $6(0.6)$ & $6(0.6)$ \\
\hline GVHD & 99,921 & 3 & $3(0.3)$ & \\
\hline Hemochromatosis & 220,489 & 5 & $5(0.5)$ & $5(0.5)$ \\
\hline Hepatic trauma & & 1 & & \\
\hline Hepatoblastoma (neoplasia) & 449 & 55 & $55(5.3)$ & \\
\hline Hepatocellular (neoplasia) & 88,673 & 19 & $19(1.8)$ & \\
\hline Hepatocellular carcinoma_Fibrolamellar (neoplasia) & 401,920 & 2 & $2(0.2)$ & \\
\hline Isolated Congenital hepatic fibrosis & 485,426 & 19 & $19(1.8)$ & $19(2.1)$ \\
\hline Langherans cell histiocytosis & 389 & 3 & $3(0.3)$ & \\
\hline Metabolic disease-Cystic fibrosis & 586 & 17 & $17(1.6)$ & $17(1.9)$ \\
\hline Metabolic disease-Others & 91,088 & 49 & $49(4.7)$ & $49(5.4)$ \\
\hline Metabolic disease_-Primary hyperoxaluria & 416 & 25 & $25(2.4)$ & $25(2.8)$ \\
\hline Metabolic disease-Tyrosinemia & $882 / 28378 / 68,723$ & 11 & $11(1.1)$ & $11(1.2)$ \\
\hline $\begin{array}{l}\text { Methylmalonic acidemia with homocystinuria, type } \\
\text { cblD }\end{array}$ & 79,283 & 3 & $3(0.3)$ & $3(0.3)$ \\
\hline $\begin{array}{l}\text { Neonatal intrahepatic cholestasis caused by citrin } \\
\text { deficiency }\end{array}$ & 247,598 & 1 & $1(0.1)$ & $1(0.1)$ \\
\hline Other neoplasia & & 7 & & \\
\hline Other rare liver diseases & $\#$ & 26 & $26(2.5)$ & \\
\hline Polycystic liver disease & 2924 & 6 & $6(0.6)$ & $6(0.6)$ \\
\hline Progressive familial intrahepatic cholestasis & 172 & 36 & $36(3.5)$ & $36(4.0)$ \\
\hline Wilson disease & 905 & 18 & $18(1.7)$ & $18(2.0)$ \\
\hline
\end{tabular}

Tx: transplants; GVHD: graft-versus-host disease; \# several ORPHA codes

reported in literature showing that worldwide there is a milder male predominance among kidney transplant patients (32, 33).

When considering the graft survival, as expected (34), a clear statistically significant difference can be highlighted comparing the pediatric and adult cohorts, with the former group showing the best survival at ten years after transplants. The only exception, but in line with reported data $(20,35)$, is represented by lung, probably in part as a consequence of the over-representation of cystic fibrosis 

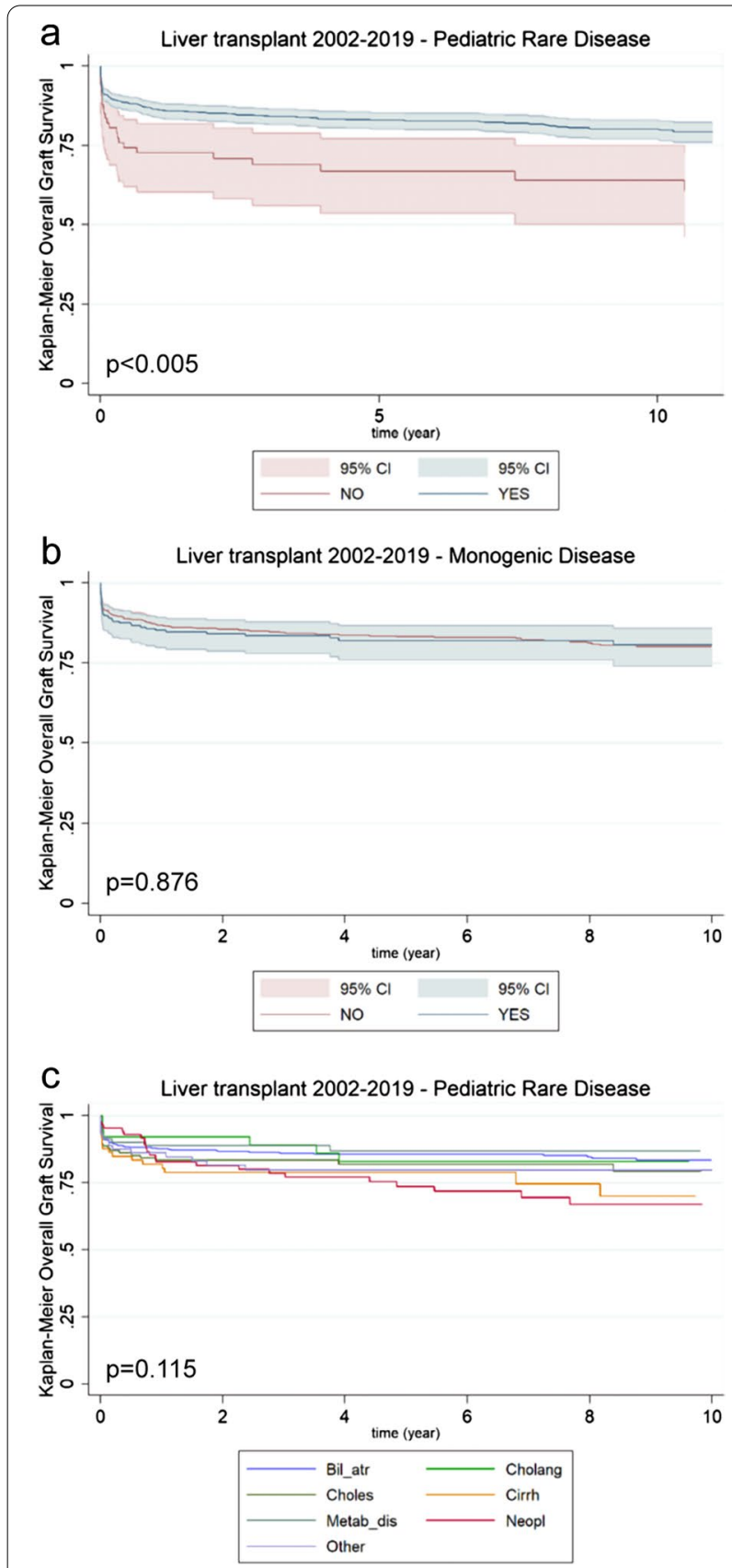

Fig. 4 Survival of liver transplanted patients in the 2002-2019 timeframe. a Kaplan-Meier curves comparing pediatric patients affected by rare diseases (green line; $n=900$ ) vs. pediatric patients affected by non-rare diseases (red line; $n=67$ ) [ $p<0.005]$. b KaplanMeier curves comparing pediatric patients affected by monogenic diseases (green line; $n=227$ ) vs. pediatric patients affected by rare non-monogenic diseases (red line; $n=673$ ) $[p=0.876]$. d KaplanMeier curves comparing pediatric patients affected by rare diseases stratified on the basis of their diagnosis $[p=0.11]$ : biliary atresia (Bil_ atr; blue line; $n=420$ ); cholestasis (Choles; light green line; $n=116$ ); metabolic diseases (Metab_dis; grey line; $n=92$ ); Cholangitis (Cholang; green line; $n=40)$; cirrhosis (Cirrh; yellow line; $n=73$ ); neoplasia (Neopl; red line; $n=86$ ); other diseases (Other; purple line; $n=73)$
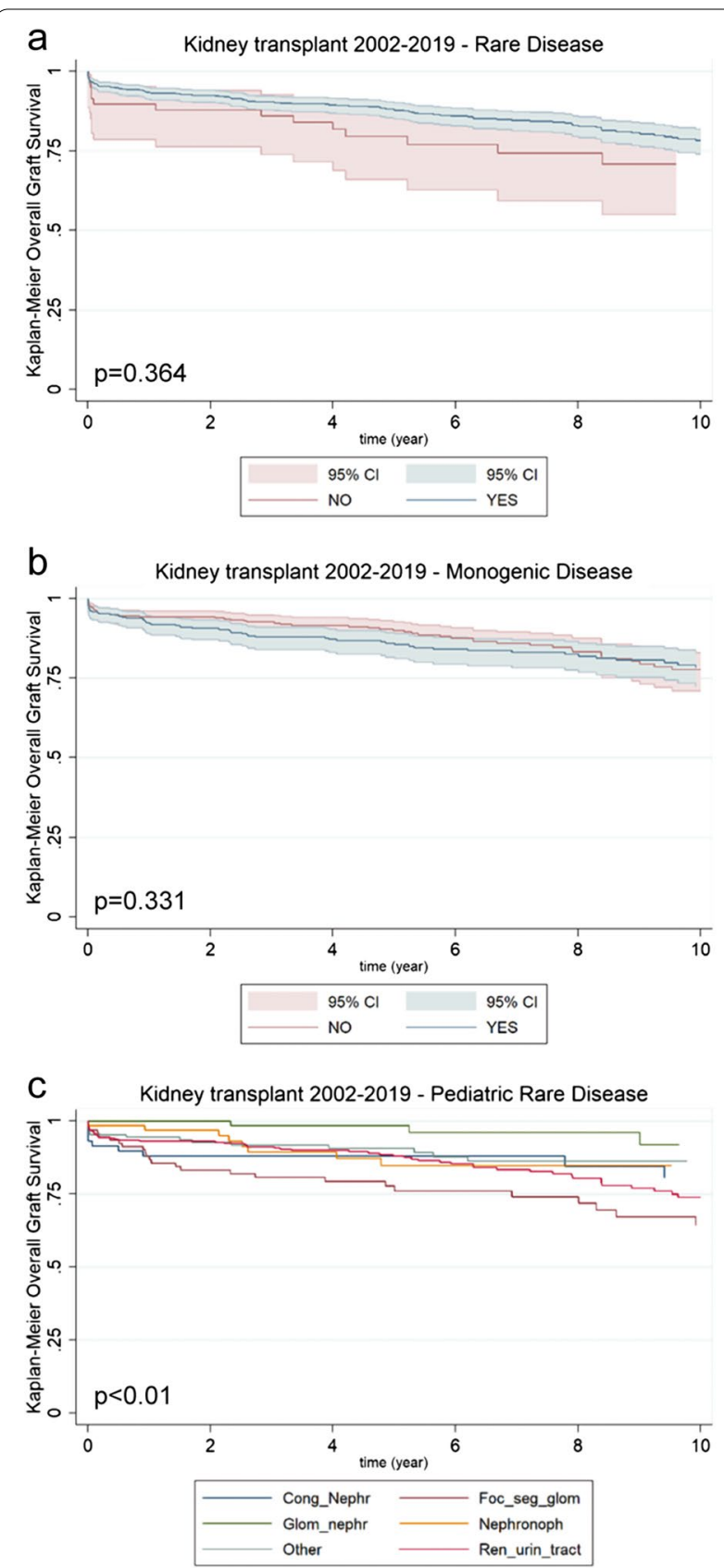

Fig. 5 Survival of kidney transplanted patients in the 2002-2019 timeframe. a Kaplan-Meier curves comparing pediatric patients affected by rare diseases (green line; $n=758$ ) vs. pediatric patients affected by non-rare diseases (red line; $n=59$ ) $[p=0.364]$. b KaplanMeier curves comparing pediatric patients affected by monogenic diseases (green line; $n=367$ ) vs. pediatric patients affected by rare non-monogenic diseases (red line; $n=391$ ) $[p=0.331]$. $\mathbf{d}$ Kaplan-Meier curves comparing pediatric patients affected by rare diseases stratified on the basis of their diagnosis $[p<0.01]$ : congenital nephrosis (Cong_Nephr; blue line; $n=59$ ); glomerular nephrosis (Glom_nephr; green line; $n=84$ ); focal segmental glomerulosclerosis (Foc_seg_glom; red line; $n=95$ ); nephronophtisis (Nephronoph; yellow line; $n=65)$; renal and urinary tract disorders (Ren_urin_tract; pink line; $n=326$ ); other diseases (Other; purple line; $n=129$ ) 
Table 9 Diagnostic categories in kidney transplanted pediatric cohort and distribution between rare and monogenic diseases

Diagnosis

Alport syndrome

Autosomal dominant tubulointerstitial kidney disease

Autosomal dominant tubulointerstitial kidney disease due to HNF1B

Autosomal dominant tubulointerstitial kidney disease due to UMOD mutation

Autosomal recessive polycystic kidney disease

Bardet-Biedl syndrome

Branchiootorenal syndrome

Caroli Disease

CHARGE syndrome

Congenital nephrotic syndrome

Congenital nephrotic syndrome type 4

Congenital nephrotic syndrome Finnish type

Congenital nephrotic syndrome type 2

Congenital nephrotic syndrome type 3

Cranioectodermal dysplasia

Cystinosis

Dense deposit disease

Denys-Drash syndrome

Ellis-Van Creveld syndrome

Fabry disease

Familial vesicoureteral reflux

Fanconi syndrome

Fechtner syndrome

Focal segmental glomerulosclerosis

Frasier syndrome

Glomerulonephritis

Goodpasture disease

Granulomatosis with polyangiitis

Hemolytic uremic syndrome

Henoch-Schonlein purpura

Hepatorenal syndrome

Hereditary endotheliopathy-retinopathy-nephropathystroke (HERNS) syndrome

Hypertensive nephrosclerosis

Hypoplastic kidneys

IgA nephropathy

Jeune syndrome

Joubert syndrome with oculorenal anomalies

Leopard syndrome

Lowe oculocerebrorenal syndrome

Lupus nephritis

Megaureter syndrome with oculorenal anomalies

Membranous nephropathy

Methylmalonic acidemia

Microscopic polyangiitis

Mitochondrial DNA-associated Leigh syndrome

Nail-patella syndrome
ORPHA code Tx (n. 887) Rare diseases (n. 837) Monogenic diseases (n. 413)

n. (\% in respect to total Tx) $n$. (\% respect to rare diseases)

$27(3.0)$

$27(3.3)$

$3(0.4)$

$1(0.1)$

$1(0.1)$

$88,9501(0$.

$43(5.2)$

$4(0.5)$

5 (0.6)

$1(0.1)$

$1(0.1)$

$1(0.1)$

$6(0.7)$

$34(4.1)$

$17(2.1)$

$2(0.2)$

$1(0.1)$

16 (1.9)

$6(0.7)$

$1(0.1)$

$1(0.1)$

$12(1.4)$

$1(0.1)$

$1(0.1)$

$72(8.7)$

2 (0.2)

$1(0.1)$

26 (3.1)

26 (2.9)

$1(0.1)$

$1(0.1)$

$1(0.1)$

63,261

$10(1.1)$

$\begin{array}{lll}93,101 & 10 & 10(1.1 \\ 761 & 8 & 8(0.9)\end{array}$

$\begin{array}{lll}474 & 1 & 1(0.1)\end{array}$

$1(0.1)$

$13(1.6)$

$1(0.1)$

$2(0.2)$

$2(0.2)$

$8(0.9)$

$1(0.1)$

$3(0.3)$

$2(0.2)$

$2(0.2)$

$3(0.3)$

$2(0.2)$

$2(0.2)$

$1(0.1)$ 
Table 9 (continued)

\begin{tabular}{|c|c|c|c|c|}
\hline Diagnosis & ORPHA code & Tx (n. 887) & $\begin{array}{l}\text { Rare diseases ( } \mathrm{n.} \mathrm{837)} \\
\text { n. (\% in respect to total Tx) }\end{array}$ & $\begin{array}{l}\text { Monogenic diseases ( } n .413) \\
\text { n. }(\% \text { respect to rare diseases) }\end{array}$ \\
\hline Neonatal cortical necrosis & & 13 & & \\
\hline Nephronophthisis & 655 & 71 & $71(8.0)$ & $71(8.6)$ \\
\hline Nephropathy due to chemotherapy & & 1 & & \\
\hline Neurogenic bladder & 84,085 & 2 & $2(0.2)$ & \\
\hline Other nephropathy & & 31 & & \\
\hline Primary hyperoxaluria type 1 & 93,598 & 14 & $14(1.6)$ & $14(1.7)$ \\
\hline Primary hyperoxaluria type 2 & 93,599 & 1 & $1(0.1)$ & $1(0.1)$ \\
\hline Prune belly syndrome & 2970 & 9 & $9(1.0)$ & $9(1.1)$ \\
\hline Renal agenesis & 411,709 & 7 & $7(0.8)$ & \\
\hline Renal coloboma syndrome & 1475 & 3 & $3(0.3)$ & $3(0.4)$ \\
\hline Renal or urinary tract malformation & 93,545 & 327 & $327(36.9)$ & \\
\hline $\begin{array}{l}\text { Renal-hepatic-pancreatic dysplasia-Dandy-Walker cysts } \\
\text { syndrome }\end{array}$ & 3032 & 1 & $1(0.1)$ & $1(0.1)$ \\
\hline Schimke immune-osseous dysplasia & 1830 & 1 & $1(0.1)$ & $1(0.1)$ \\
\hline Sirenomelia & 3169 & 1 & $1(0.1)$ & $1(0.1)$ \\
\hline $\begin{array}{l}\text { Split hand urinary anomalies spina bifida (Czeizel-Losonci } \\
\text { syndrome) }\end{array}$ & & 2437 & 4 & $4(0.5)$ \\
\hline Townes-Brocks syndrome & 857 & 1 & $1(0.1)$ & $1(0.1)$ \\
\hline Trauma & & 1 & & \\
\hline VACTERLNACTER association & 887 & 2 & $2(0.2)$ & $2(0.2)$ \\
\hline Vasculitis & 52,759 & 7 & $7(0.8)$ & \\
\hline Wilms tumor & 654 & 2 & $2(0.2)$ & \\
\hline
\end{tabular}

Tx: transplants

both in children and adults. Within the pediatric cohort, a diagnosis of rare or monogenic disease is not by itself sufficient to predict graft survival probability. Indeed, a clear and unique trend was not evident by this analysis.

Overall, this survey has drawn attention on the significant proportion of patients included in a waiting list or already transplanted who lack a disease diagnosis at the time of transplant (25-27). Moreover, a prominent quote of patients requiring organ transplantation are affected by rare and monogenic diseases $(17,18)$. These data open the discussion on the possibility to improve the diagnostic power by introducing genetic testing as part of the clinical flow before organ transplants, at least for some patient categories (36-39). The availability of sequencing platforms, the possibility to design selective gene panels for the analysis as well as the reduced costs of genetic tests may be in favour of this hypothesis, while avoiding doubtful exams and diagnosis. Having the correct diagnosis of the original disease that leads to organ insufficiency is relevant for many reasons, including i) the identification of the best therapeutic window to perform transplantation, ii) prevention of post-transplant complications that can be related to the original disease, iii) adoption of specific therapeutic regimens. This issue becomes even more relevant for rare and monogenic diseases where the genetic testing is crucial for a univocal diagnosis.

A further point to be stressed is that, at least for a small proportion of these patients, novel therapeutic approaches may represent a viable alternative to transplantation. While this is currently available mostly in the context of clinical trials, it is conceivable that in the near future targeted treatments, such as gene therapy/editing and stem cell-based therapies may become available for an increasingly higher number of rare diseases (40-42).

Lastly, a final consideration regards the economic impact of transplants as a treatment strategy compared to conventional treatments. At least in Western countries, it is well known that transplantation is cost-effective compared to other options $(43,44)$. As an example, for kidney, transplantation is the best choice compared to dialysis, with an initial cost of approximately 45,000 Euros that drops-off to 8,000 Euros starting from the second year after transplantation.

\section{Conclusions}

This work was designed to provide an updated snapshot of organ transplants in Italy, considered from a genetic perspective. We went through the Italian Transplant 


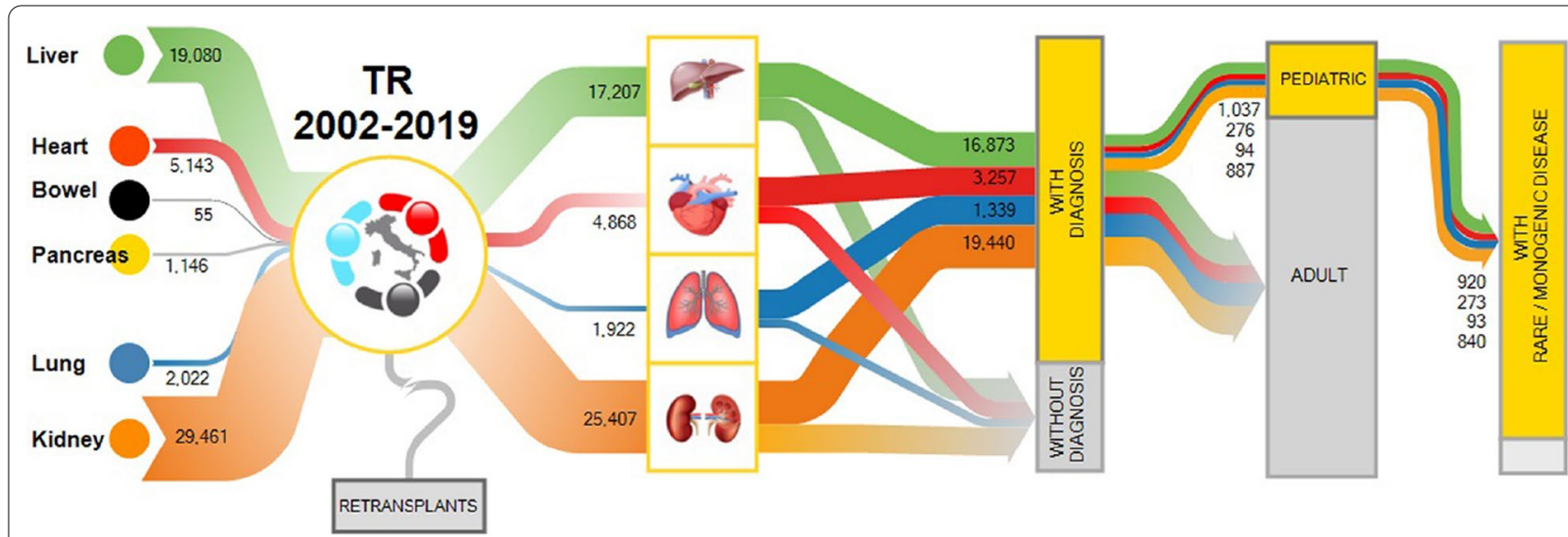

Fig. 6 Sankey diagram showing the analytical flow adopted in the study. The diagram showed the different parameters that were taking into account in the present analyses: transplanted patients registered in the transplanted register (TR) in the 2002-2019 timeframe, cohort selection and inclusion/exclusion criteria, classification on the basis of presence/absence of a diagnosis indicated in the TR, analysis of the pediatric cohort based on a diagnosis of rare and/or monogenic diseases. Single pancreas and bowel transplants were excluded from the analysis, as well as re-transplanted patients

Registry, considering both the adult and pediatric cohorts, focusing on disease diagnoses that lead to organ failure finally requiring transplants (Fig. 6). Remarkably, in 1 patient out of 5 , transplantation was performed in patients lacking a diagnosis. Within the diagnosed subset, the great majority of the pediatric patients presented with rare genetic diseases, most of them being affected by monogenic pathologies (Fig. 7).

The results of this work represent, to our knowledge, the first national survey on genetic diseases leading to organ transplants, being a novelty in the field. Moreover, they represent a starting point for future considerations on the relevance of disease diagnosis for patient management, taking into account also the increasing spread of sequencing technologies that allow for a clear genetic diagnosis.

\section{Methods}

\section{Italian transplant registry}

The Transplant Registry (TR) is entrusted to the Transplant Information System (TIS), which is an infrastructure for the management of data related to the activity of the National Transplant Network, established and regulated by Italian Laws (no. 91/99 and Decree of the Ministry of Health n. 130 of 20 August 2019).

\section{Clinical data and rare and monogenic disease diagnosis}

Several data are collected by the TR, including patients' demographic and clinical information, survival after transplant, and indication of the disease that caused endstage organ failure. To this purpose, a specific in series classification is used for each organ to define macro- and sub-categories of pathologies, the latter used to provide more detailed features of the diagnosis.

To identify rare and monogenic diseases in our cohort, a list of these pathologies was generated, matching entries from the National Organization for Rare Disorders (NORD; https://rarediseases.org/), Orphanet database (https://www.orpha.net/), the Genetic and Rare diseases information center (NIH-GARD, https://rared iseases.info.nih.gov/) and Online Mendelian Inheritance in Man catalog (OMIM, https://www.omim.org/). In the case of the kidney, the available diagnosis in the TR did not allow for an unambiguous classification, and the pediatric kidney transplant centers were asked to fill in a specific form in order to identify the diagnosis of the disease in a more precise manner, allowing for rare and monogenic disease classification.

\section{Statistical analyses}

The Kaplan-Meier method was used to analyze overall graft survival (death non censored graft survival). These analyses were carried out considering transplant recipients i) with a follow up and ii) that underwent a first transplant. The corresponding number of patients considered are indicated in the figure legends. The log rank test was used to evaluate the statistical significance. For the age of registration in the transplant list and the age at transplant for the pediatric cohort, values were expressed as median (interquartile range) unless otherwise specified. The Shapiro-Wilk normality test was used to evaluate normality distribution for continuous or ordinal dependent variable. Kruskal-Wallis test was used to assess for significant differences on a continuous 


\section{Key points \\ 1. $82.8 \%$ of transplants recorded in the TR have a defined diagnosis}

\section{2. $5.6 \%$ of the transplants in Italy involves} children, with the higher percentage $(8.9 \%)$ reached for heart transplants and the lower $(3.7 \%)$ for kidney

\section{Liver, kidney and heart are the most frequently transplanted organs in pediatric patients}

4. There are more than one hundred different diseases that cause organ failure, requiring transplantation

\section{5. $91.4 \%$ of these conditions belongs to the rare diseases category}

6. $92.7 \%$ of pediatric patients undergoing organ transplants are affected by rare diseases

7. $61.1 \%$ of transplanted pediatric patients are diagnosed with a monogenic disease

8. The proportion of pediatric patients with monogenic diseases varies according to the transplanted organ: $80.8 \%$ for heart; $87.2 \%$ for lung; $66.2 \%$ for liver; $46.3 \%$ for kidney

9. Pediatric transplants, except for lung, are characterized by a better overall graft survival compared to adult transplanted patients

Fig. 7 Key points of the study. Highlights of the study emerging from this national survey of patients included in National Transplants Registry

dependent variable. $\mathrm{P}$ values $<0.05$ were considered statistically significant. All data were analyzed using STATA (v 16.1 Copyright 1985-2019 StataCorp LP 4905 Lakeway Drive College Station, Texas 77,845 USA).

\section{Supplementary Information}

The online version contains supplementary material available at https://doi. org/10.1186/s13023-021-02013-x.

Additional file 1. Additionale file 1 includes Supplementary Table 1 showing combined transplants in the pediatricand adult cohorts included in the study and a Supplementary Table 2 listing Transplant Centers that enrolledpediatric and adult patients included in the study and present in the Transplant Registry.

\section{Acknowledgements}

This study was carried out thanks to the support and cooperation of the Italian National Transplant Network. We wish to thank staff at Transplant Centres, the hospitals that took care of waitlisted and transplanted patients, as well as those that made organ donation possible. Finally, yet importantly, our deepest gratitude is for the donor families, whose generosity makes, each day, transplantation accessible for many patients.

\section{Authors' contributions}

TV, DP, PM, AR, LL, SD, MC and A. Amoroso designed research, analyzed results and wrote the manuscript; E. Gringeri, SC, M. Spada, SM, ADG, GL, MV, GG, AT, CPN, A. Amodeo, LR, LdS, EB, IF, ST, LP, AM, AS, CG, E. Gotti, M. Schiavon, MB, $\mathrm{DDA}, \mathrm{AB}, \mathrm{DP}, \mathrm{MT}, \mathrm{CP}$ provided diagnosis and clinical data about the pediatric cohort. All authors read and approved the final manuscript.

\section{Funding}

This work was supported by the Italian Ministry of Education (Progetto strategico di Eccellenza Dipartimentale \#D15D18000410001, awarded to the Department of Medical Sciences, University of Turin; members: T. Vaisitti, S. Deaglio and A. Amoroso) and by Regione Piemonte (DD 803 25.11.2019 to A. Amoroso).

\section{Availability of data and materials}

The datasets generated and/or analysed during the current study are not publicly available since they are part of the National Transplantation Center only, but are available from the corresponding author on reasonable request.

\section{Declarations}

\section{Ethics approval and consent to participate}

All patients included in TR consented to registration and use of their data, which were treated and analysed in compliance with the European General Data Protection Regulation (EU GDPR), anonymizing sensitive data and processing aggregate data. National Transplant Center Data Protection Officer (DPO) authorized this study. The study has been approved by the Ethics Committee of the Italian "Istituto Superiore di Sanità" (PRE BIO CE 01.00 - 0015976).

\section{Consent for publication}

Not applicable.

\section{Competing interests}

The authors declare that they have no competing interests.

\section{Author details}

'Department of Medical Sciences, University of Torino, Via Nizza 52, 10126 Torino, Italy. ${ }^{2}$ National Transplant Center, Istituto Superiore Di Sanità, Roma, Italy. ${ }^{3}$ Immunogenetics and Transplant Biology, Azienda Ospedaliera Universitaria Città Della Salute E Della Scienza Di Torino, Torino, Italy. ${ }^{4}$ Hepatobiliary Surgery and Liver Transplantation Unit, Padova University Hospital, Padova, Italy. ${ }^{5}$ General Surgery 2 U - Liver Transplant Center, Azienda Ospedaliera Universitaria Città Della Salute E Della Scienza Di Torino, University of Turin, Torino, Italy. ${ }^{6}$ Divison of Hepatobiliopancreatic Surgery, Liver and Kidney Transplantation, Research Unit of Clinical Hepatogastroenterology and Transplantation, Bambino Gesù Children's Hospital, IRCCS, Rome, Italy. ${ }^{7}$ Department of Pediatrics, Ismett, Palermo, Italy. ${ }^{8}$ Paediatric Hepatology, Gastroenterology and Transplantation, Papa Giovanni XXIII Hospital, Bergamo, Italy. ${ }^{9}$ Center for Coordination on rare diseases - Regione Campania, Cardiovascular Rare and Genetic Diseases Unit, Department of Cardiology, Monaldi Hospital, AORN Dei Colli,, Naples, Italy. ${ }^{10}$ DeGasperis CardioCenter, Niguarda Great Metropolitan Hospital, Milan, Italy. ${ }^{11}$ Heart Transplantation Unit, Cardio-Thoraco-Vascular Sciences and Public Health Department, University Padova Hospital, Padova, Italy. ${ }^{12}$ UOS Transplantation Surgery, Asst Papa Giovanni XXIII Hospital, Bergamo, Italy. ${ }^{13}$ Pediatric Cardiac Surgery and Congenital Cardiopathies Unit, Regina Margherita Children's Hospital, Azienda Ospedaliera Città Della Salute E Della Scienza Di Torino, Turin, Italy. ${ }^{14}$ Bambino Gesù Children's Hospital, IRCCS, Rome, Italy. ${ }^{15}$ Paediatric Cardiology and ACHD Unit, S. Orsola, Malpighi Hospital, Bologna, Italy. ${ }^{16}$ Renal Transplant Unit. Bambino Gesù Children's Research Hospital IRCCS, Rome, Italy. ${ }^{17}$ Pediatric Nephrology, Dialysis and Transplant Unit, Department of Women's and Children's Health, Padua University Hospital, Padua, Italy. ${ }^{18}$ Azienda Ospedaliera 
Universitaria San Martino, Genoa, Italy. ${ }^{19}$ Pediatric Nephrology, Dialysis and Transplant Unit, Fondazione IRCCS Ca' Granda-Ospedale Maggiore Policlinico, Milan, Italy. ${ }^{20}$ Pediatric Nephrology Unit, Regina Margherita Children's Hospital, Azienda Ospedaliera Universitaria Città Della Salute E Della Scienza Di Torino, Turin, Italy. ${ }^{21}$ Azienda Ospedaliera, Universitaria Policlinico Di Bari, Bari, Italy. ${ }^{22}$ Department of Pediatrics, Ismett, Palermo, Italy. ${ }^{23}$ Nephrology, Dialysis and Kidney Transplant Unit, IRCCS Azienda Ospedaliero-Universitaria Di Bologna, Bologna, Italy. ${ }^{24}$ Unit of Nephrology, Azienda Socio Sanitaria Territoriale Papa Giovanni XXIII, Bergamo, Italy. ${ }^{25}$ Thoracic Surgery and Lung Transplant Unit, Department of Cardiac, Thoracic, Vascular Sciences and Public Health, University Hospital of Padua, Padua, Italy. ${ }^{26}$ Heart and Lung Transplant Center, Cardiac Surgery Division, Surgical Sciences Department, University of Torino, Torino, Italy. ${ }^{27}$ Bambino Gesù Children'sHospital, IRCCS, Rome, Italy. ${ }^{28}$ Division of Thoracic Surgery and Lung Transplantation, Department for the Treatment and Study of Cardiothoracic Diseases and Cardiothoracic Transplantation, IRCCS-ISMETT, Palermo, Italy. ${ }^{29}$ Department of Organ Failure and Transplantation, ASST Giovanni XXIII, Bergamo, Italy. ${ }^{30}$ Ospedale Maggiore Policlinico, Milan, Italy. ${ }^{31}$ Department of Thoracic Surgery, Policlinico Umberto I Hospital, University of Rome Sapienza, Rome, Italy.

Received: 26 May 2021 Accepted: 24 August 2021

Published online: 04 September 2021

\section{References}

1. Schieppati A, Henter JI, Daina E, Aperia A. Why rare diseases are an important medical and social issue. Lancet. 2008;371(9629):2039-41.

2. Liu BC, He L, He G, He Y. A cross-national comparative study of orphan drug policies in the United States, the European Union, and Japan: towards a made-in-China orphan drug policy. J Public Health Policy. 2010;31(4):407-20.

3. Bolk S, Puffenberger EG, Hudson J, Morton DH, Chakravarti A. Elevated frequency and allelic heterogeneity of congenital nephrotic syndrome, Finnish type, in the old order Mennonites. Am J Hum Genet. 1999;65(6):1785-90.

4. OMIM: Online Mendelian Inheritance in Man [Available from: https:// www.omim.org/statistics/entry

5. Wright CF, FitzPatrick DR, Firth HV. Paediatric genomics: diagnosing rare disease in children. Nat Rev Genet. 2018;19(5):325.

6. Boycott KM, Rath A, Chong JX, Hartley T, Alkuraya FS, Baynam G, et al. International Cooperation to Enable the Diagnosis of All Rare Genetic Diseases. Am J Hum Genet. 2017;100(5):695-705.

7. Farnaes L, Hildreth A, Sweeney NM, Clark MM, Chowdhury S, Nahas S, et al. Rapid whole-genome sequencing decreases infant morbidity and cost of hospitalization. NPJ Genom Med. 2018;3:10.

8. Kochanek KD, Murphy S, Xu J, Arias E. Mortality in the United States, 2016. NCHS Data Brief. 2017;293:1-8.

9. O'Malley M, Hutcheon RG. Genetic disorders and congenital malformations in pediatric long-term care. J Am Med Dir Assoc. 2007;8(5):332-4.

10. Synnes AR, Berry M, Jones H, Pendray M, Stewart S, Lee SK, et al. Infants with congenital anomalies admitted to neonatal intensive care units. Am J Perinatol. 2004;21(4):199-207.

11. Ferreira CR. The burden of rare diseases. Am J Med Genet A. 2019;179(6):885-92.

12. Starzl TE. History of clinical transplantation. World J Surg. 2000;24(7):759-82.

13. Zuber K, Howard T, Davis J. Transplant in the 21 st century. JAAPA. 2014;27(11):26-34.

14. Merion RM, Schaubel DE, Dykstra DM, Freeman RB, Port FK, Wolfe RA. The survival benefit of liver transplantation. Am J Transplant. 2005;5(2):307-13.

15. Schaubel DE, Sima CS, Goodrich NP, Feng S, Merion RM. The survival benefit of deceased donor liver transplantation as a function of candidate disease severity and donor quality. Am J Transplant. 2008;8(2):419-25.

16. Europe TECo. Council of Europe portal2020 [Available from: https://www. edqm.eu/en/reports-and-publications.

17. Quaglia M, Musetti C, Ghiggeri GM, Fogazzi GB, Settanni F, Boldorini RL, et al. Unexpectedly high prevalence of rare genetic disorders in kidney transplant recipients with an unknown causal nephropathy. Clin Transplant. 2014;28(9):995-1003.

18. Schrezenmeier E, Kremerskothen E, Halleck F, Staeck O, Liefeldt L, Choi M, et al. The underestimated burden of monogenic kidney disease in adults waitlisted for kidney transplantation. Genet Med. 2021

19. Hayes D Jr, Cherikh WS, Chambers DC, Harhay MO, Khush KK, Lehman RR, et al. The International Thoracic Organ Transplant Registry of the International Society for Heart and Lung Transplantation: Twenty-second pediatric lung and heart-lung transplantation report-2019; Focus theme: Donor and recipient size match. J Heart Lung Transplant. 2019;38(10):1015-27.

20. Kirkby S, Hayes D Jr. Pediatric lung transplantation: indications and outcomes. J Thorac Dis. 2014;6(8):1024-31.

21. Fagiuoli S, Daina E, D’Antiga L, Colledan M, Remuzzi G. Monogenic diseases that can be cured by liver transplantation. J Hepatol. 2013;59(3):595-612.

22. Azzi Y, Bartash R, Scalea J, Loarte-Campos P, Akalin E. COVID-19 and Solid Organ Transplantation: A Review Article. Transplantation. 2021;105(1):37-55.

23. Galvan NTN, Moreno NF, Garza JE, Bourgeois S, Hemmersbach-Miller M, Murthy B, et al. Donor and transplant candidate selection for solid organ transplantation during the COVID-19 pandemic. Am J Transplant. 2020;20(11):3113-22.

24. Ottlewski I, Munch J, Wagner T, Schonauer R, Bachmann A, Weimann A, et al. Value of renal gene panel diagnostics in adults waiting for kidney transplantation due to undetermined end-stage renal disease. Kidney Int. 2019;96(1):222-30.

25. Kramer A, Pippias M, Noordzij M, Stel VS, Afentakis N, Ambuhl PM, et al. The European Renal Association - European Dialysis and Transplant Association (ERA-EDTA) Registry Annual Report 2015: a summary. Clin Kidney J. 2018;11(1):108-22.

26. Saran R, Li Y, Robinson B, Abbott KC, Agodoa LY, Ayanian J, et al. US Renal Data System 2015 Annual Data Report: Epidemiology of Kidney Disease in the United States. Am J Kidney Dis. 2016;67(3 Suppl 1):Svii, S1-305.

27. Titze S, Schmid M, Kottgen A, Busch M, Floege J, Wanner C, et al. Disease burden and risk profile in referred patients with moderate chronic kidney disease: composition of the German Chronic Kidney Disease (GCKD) cohort. Nephrol Dial Transplant. 2015;30(3):441-51.

28. Harness-Brumley CL, Elliott AC, Rosenbluth DB, Raghavan D, Jain R. Gender differences in outcomes of patients with cystic fibrosis. J Womens Health (Larchmt). 2014;23(12):1012-20.

29. Konstan MW, Morgan WJ, Butler SM, Pasta DJ, Craib ML, Silva SJ, et al. Risk factors for rate of decline in forced expiratory volume in one second in children and adolescents with cystic fibrosis. J Pediatr. 2007;151(2):134-9.

30. Sweezey NB, Ratjen F. The cystic fibrosis gender gap: potential roles of estrogen. Pediatr Pulmonol. 2014;49(4):309-17.

31. McIntyre K. Gender and survival in cystic fibrosis. Curr Opin Pulm Med. 2013;19(6):692-7.

32. Bikbov B, Perico N, Remuzzi G, on behalf of the GBDGDEG. Disparities in Chronic Kidney Disease Prevalence among Males and Females in 195 Countries: Analysis of the Global Burden of Disease 2016 Study. Nephron. 2018;139(4):313-8.

33. Tomlinson LA, Clase CM. Sex and the incidence and prevalence of kidney disease. Clin J Am Soc Nephrol. 2019;14(11):1557-9.

34. Dayoub JC, Cortese F, Anzic A, Grum T, de Magalhaes JP. The effects of donor age on organ transplants: a review and implications for aging research. Exp Gerontol. 2018;110:230-40.

35. Goldfarb SB, Levvey BJ, Edwards LB, Dipchand Al, Kucheryavaya AY, Lund $\mathrm{LH}$, et al. The registry of the international society for heart and lung transplantation: nineteenth pediatric lung and heart-lung transplantation report-2016; focus theme: primary diagnostic indications for transplant. J Heart Lung Transplant. 2016;35(10):1196-205.

36. Bullich G, Domingo-Gallego A, Vargas I, Ruiz P, Lorente-Grandoso L, Furlano $\mathrm{M}$, et al. A kidney-disease gene panel allows a comprehensive genetic diagnosis of cystic and glomerular inherited kidney diseases. Kidney Int. 2018;94(2):363-71.

37. Groopman EE, Marasa M, Cameron-Christie S, Petrovski S, Aggarwal VS, Milo-Rasouly $\mathrm{H}$, et al. Diagnostic utility of exome sequencing for kidney disease. N Engl J Med. 2019;380(2):142-51.

38. Lata S, Marasa M, Li Y, Fasel DA, Groopman E, Jobanputra V, et al. Wholeexome sequencing in adults with chronic kidney disease: a pilot study. Ann Intern Med. 2018;168(2):100-9. 
39. Vaisitti T, Sorbini M, Callegari M, Kalantari S, Bracciama V, Arruga F, et al. Clinical exome sequencing is a powerful tool in the diagnostic flow of monogenic kidney diseases: an Italian experience. J Nephrol. 2020.

40. Cossu G, Birchall M, Brown T, De Coppi P, Culme-Seymour E, Gibbon S, et al. Lancet commission: stem cells and regenerative medicine. Lancet. 2018;391(10123):883-910

41. Lapteva L, Vatsan R, Purohit-Sheth T. Regenerative medicine therapies for rare diseases. TransI Sci Rare Dis. 2018;3(3-4):121-32.

42. Tambuyzer E, Vandendriessche B, Austin CP, Brooks PJ, Larsson K, Miller Needleman Kl, et al. Therapies for rare diseases: therapeutic modalities, progress and challenges ahead. Nat Rev Drug Discov. 2020;19(2):93-111.
43. Tissen JCAJ, B.; Rabinovich, L.; de Vries, H.; Hatziandreu, E.; Patruni, B.; Ling, T. Improving organ donation and transplantation in the European Union. 2008.

44. Van der Spiegel S. Economic costs and benefits of transplantation. European Commission; 2013.

\section{Publisher's Note}

Springer Nature remains neutral with regard to jurisdictional claims in published maps and institutional affiliations.
Ready to submit your research? Choose BMC and benefit from:

- fast, convenient online submission

- thorough peer review by experienced researchers in your field

- rapid publication on acceptance

- support for research data, including large and complex data types

- gold Open Access which fosters wider collaboration and increased citations

- maximum visibility for your research: over $100 \mathrm{M}$ website views per year

At BMC, research is always in progress.

Learn more biomedcentral.com/submissions 